\title{
A Study on Effectiveness of Community De-Addiction Camp at Chamarajanagar
}

\author{
Suman K. Murthy ${ }^{1 *}$, S. Adarsh ${ }^{2}$, Leelu Prasad Madhav ${ }^{3}$, K. G. Mahesh ${ }^{4}$, T. M. Nandeesha ${ }^{5}$ \\ ${ }^{1}$ Associate Professor \& Head, Department of Social Work, ${ }^{2,3,4 \& 5}$ PG Students, MSW Course \\ ${ }^{1,2,3,4 \& 5}$ Pooja Bhagavat Memorial Mahajana Education Centre, Mysuru, Karnataka \\ *CorrespondingAuthor \\ E-Mail: sumankeshavamurthy@gmail.com
}

\begin{abstract}
Alcohol addiction is a serious health hazard which has negative consequences for the affected individual as well as his family and community. Inpatient based de addiction treatment is commonly seen to tackle the problem of addiction. Of late, Community de addiction camps are providing de addiction treatment at community level in India. The current study looks into the impact of exposure to community de addiction camp organized by SKDRDP, Chamarajanagar, Karnataka State, India. Qualitative experimental research design is adopted to study the impact of exposure to the community de addiction camp. The total duration of the residential community de addiction camp was eight days. The universe for the study comprised of 103 participants attending the community de addiction camp. 40 participants formed the sample. Tools used for gathering the data were WHO-AUDIT, Interview schedule and participant observation. The data were analysed using paired t- test using SPSS version version22.0 and participant observation recordings. The community de addiction camp has met all the thirteen expectations of the participants with regard to the camp; The result of t-test found that there is statistically significant difference in the mean scores on all parameters between before and after de addiction camp; there exists significant positive relationship between Clint behavior and client participation before the community de addiction camp. The participants had a positive impact from the exposure to the camp, which was evident to the researchers who were participant observers of the whole process. The community de addiction camp has been successful in bringing about a positive impact on the participants during the conduct of the camp and abstinence was $100 \%$ at 1 month post camp follow up. In view of these findings, the current study concludes that community de addiction camps have a positive impact on the participants. Community de addiction camps are an effective and economical way to combat alcohol addiction at the community level.
\end{abstract}

Keywords: Community De Addiction Camp, Social Work Interventions

\section{INTRODUCTION}

In general parlance alcoholism means, the habitual consumption of alcoholic liquor in increasing quantities, leading to a dependence on alcohol and creating problems for the individual concerned, his family and the society. Alcohol consumption is the world's third largest risk factor for disease and disability and is associated with many serious socio-economic issues, including violence, child neglect and abuse, and absenteeism at the workplace. Approximately $4.5 \%$ of the Global Burden of Disease and injury is attributable to alcohol use. Measures of problems from alcohol consumption, including estimates of alcohol as a risk factor in the Global Burden of Disease, have primarily focused on harm to the drinker's health. Yet it is clear that drinking often also causes harm to the health and welfare of others around the drinker - to family members and friends, and to others in the community and more broadly. Recent studies from India, including the SEARO Bangalore study, the India arm of the WHO-GENACIS study and the WHONIMHANS study on Alcohol Related Harms in the Community suggested that persons in close contact with the alcohol user suffered disproportionate harms to health, and social and economic wellbeing.

\section{REVIEW OF LITERATURE}

Alcohol addiction, a chronic relapsing disorder, is a fast growing public health problem in India. The production, availability, consumption and drinking patterns of alcohol have all undergone phenomenal changes in India and have been influenced by the combined effects of globalization, market forces, changing government policies, media promotion and also changing values of Indian society. Moreover, a large proportion of current alcohol users have hazardous or probably dependent patterns of alcohol use. In contrast to the need, the resources available to tackle this are abysmally inadequate. Most of the government funded treatment centres are defunct and the rates of help-seeking in these centres are the lowest in States with the highest prevalence of alcohol use (Chand et al., 2013).

Alcohol consumption is a culturally defined activity, impacted by the economics and polity of a society at a given point in time. In the year 2000-2001 the recorded alcohol per capita consumption in India was a low 0.82 liters of pure alcohol as compared to the per capita consumption in US (8.51 liters), Canada (8.26 liters) and UK (10.39 liters) for the same period (WHO, 2004). Post 1995, the unrecorded alcohol per capita consumption in India is an estimated 1.7 liters (WHO, 2004). While these figures give the impression that India is largely a dry culture, considerable variations exist in the prevalence of alcohol use and misuse within the country. Class, caste, religion and gender are significant factors that define the patterns and nature of alcohol consumption across India. Further, 
increasingly, globalization and economic liberalization are affecting changes in the social fabric and organization of the Indian society and is likely to have an impact on drinking patterns and cultures in the country as well (Prabhu et al., 2010).

Tonse \& Sinu (2012) conducted a study with experimental study group $(\mathrm{N}=30)$ and comparative group $(\mathrm{N}=30)$. Study group was taken in Sasthana village, KundapurTaluk, Udupi District (community based de-addiction camp (CBC) conducted by Shri K. Shethra Dharmasthala Rural Development Programme) and comparative group was taken in Dr. A.V. Baliga Hospital, Doddanagudde, Udupi District, Karnataka (hospital based de-addiction camp (HBC)). It was a Quasi-Experimental Research Design- pre and post test with control group was adopted. The objective of the study was to assess the quality of life of the person with alcohol dependence syndrome, before and after the deaddiction camp intervention in community as well as in hospital based camp intervention. Chi square test, 't' test, one-way ANOVA, Survival analysis, Effect Size analysis, correlation and regression analysis were applied to gather the results. With regard to quality of life of the respondents in both group scored less (82 in $\mathrm{CBC}$ and 86 in $\mathrm{HBC}$ ) during pre-assessment. Respondents in Hospital based Camp showed significant improvement in their psychological, environmental quality of life during postassessment. It was found that majority of the respondents in hospital based de-addiction camp had low quality of psychological health and it was also found that their severity of alcohol dependence was high $(x=39.53)$ when compared to the community based de-addiction camp ( $\mathrm{x}=31.86)$ even though HBDC respondents reported of having good physical health in quality of life. In the present study it was found that respondents in both the camps who maintained abstinence had shown significant improvement in quality of life than relapsers. This study revealed that the camp approach intervention is effective both in helping the people with alcohol dependence syndrome and in maintaining abstinence.

Lok Raj et al., (2005)carried out a 'Community 'deaddiction' camps: A follow-up study' on patients treated in two different camps and the sample was heterogeneous. Apart from abstinence, changes in the dose, and frequency and status of complications were assessed to determine the outcome. Forty-six patients diagnosed according to the ICD-10 criteria were admitted in two different camps (23 in each camp) organized in the community for 10 days each. After discharge, the patients were followed-up once a week in the community clinics of the respective villages by a team comprising a consultant psychiatrist, a medical social worker and a community nurse. The patients who dropped out were contacted through home visits by the social worker to ensure regular follow-up. Thirty-six patients remained in the study at the end of 6 months of follow-up (78.3\%). The drop-out rate was $16.3 \%$, which is far below the drop-out rate for hospital-based treatment (between 36\% and 69\%). patients who showed improvement and abstinence account for $72.7 \%$, which is significant in view of the low cost of treatment. There was also a significant reduction in drugrelated physical and familial complications.

Nithin Kumar et al., (2013) conducted a study entitled 'Profile of Substance Use among Patients Attending DeAddiction Centres in a Coastal City of Southern India'. The aim was to study the socio-demographic profile and the reasons for substance use among patients admitted at Deaddiction centres in Mangalore, India. In this cross-sectional study, all the patients admitted at the De-addiction centres during the study period were interviewed. A total of 83 patients were included in the study, all of whom were males. A positive family history of substance use was evident in $63 \%$ of the respondents. The mean age of the study participants was 41.9 (SD611.2) years and the mean age for starting substance use was 20.9 (SD67.7) years. The most common substance used was alcohol (95.2\%). Majority of the subjects $(56.6 \%)$ cited peer pressure as a reason for initiating substance use.

Sell (2003) explains the origin of 'The open community approach to drug abuse control'. This approach was developed in the South East Asia region of WHO in learning and experimenting process based on ethnographic research, over a period of about 15 years. Hypothesizing that such socialization processes leading to dependence can best be reversed by socialization processes out of dependence (irrespective of physical addiction, i.e. by working with dependent persons as groups rather than individuals), the concept of village-wise detoxification was introduced for rural opium users in Myitkyina, Myanmar and in Manaklao, Rajasthan, in the early 1980s.

In this approach, outreach workers (often ex-user volunteers) spend time in a village identifying opium users, working with them and their families in efforts to create optimism and to overcome helplessness and hopelessness. They mobilize the community and finally take as many of them as possible (ideally, of course, all of them) to an institution for detoxification together, as a festive event and common achievement. It was soon realized that there was no need for an institution, but that this mass detoxification could be even more effectively be done in the communities concerned, under trees, in tents, or in whatever accommodation the community could provide. Thus, following the outreach workers' and volunteers' community mobilization efforts, a team with some medical support moved into a community for mass detoxification, with full community support. We called this the camp approach. It was successfully adapted to rural alcohol problems in Tamil $\mathrm{Nadu}$, and to urban heroin problems in many parts of India and Sri Lanka.

Chavan et al., (2003) conducted a study entitled 'Camp Approach - an Effective, Alternate Inpatient Treatment Setting for Substance Dependence: A Report from India'. In India, from early 1980s, voluntary and government agencies have addressed health issues by organizing 'camps' - eye camps, immunization camps, family planning camps 
etc.The success of these camps prompted Indian health professionals to adopt the 'camp approach' for the treatment of substance dependence. Purohit \& Razdan (1988), probably the first to try out this approach, treated 640 cases of opioid dependence over a period of 4 years by conducting 14 camps. They reported 'camp approach' to be as effective as hospital approach, if not more effective. Datta et al., (1991) presented data on 14 DSM-III cases of alcohol dependence with gratifying results i.e. $90 \%$ being abstinent over a 1year follow-up period. Ranganathan (1994) studied 105 cases of alcohol dependence, treated in four different camps, and reported one year abstinence rate of around $85 \%$. Chavan \& Priti (1999) treated 22 cases of alcohol and opioid dependence and achieved detoxification in majority of patients.

Study by Chavan et al., (2003) found that patients treated by 'camp approach' were older, less educated but more frequently employed, with longer duration of dependence, abusing mainly alcohol and natural opioids, and with absence of comorbidity in comparison to the hospital treated patients. Both groups were, however, comparable on clinical status at discharge and at follow up after 3 months. The study concluded that the 'camp approach' is a viable and effective alternate form to inpatient treatment. A brief review of literature has shown that alcohol addiction is being treated with Community camp based de addiction treatment. A number of studies have shown that community based de addiction had positive rate of abstinence. There is a need for conduct of more research based studies to know the impact of community de addiction camps. With this context in mind, the current study is envisaged.

\section{MATERIALS AND METHODS}

The aim of the study was to study the impact of exposure to community de addiction camp of SKDRPD at Chamarajanagar on the camp participants.

\section{OBJECTIVES OF THE STUDY}

1. To gather the socio economic background and pattern of addiction of participants of community de addiction camp

2. To find out the pattern of alcohol addiction, impact of addiction and attempts at abstinence of participants of community de addiction camp

3. To identify the expectations of the participants about the community de addiction camp

4. To find out the level of AUDIT score of the participants

5. To find the relationship between the behavior and participation of the participants in the community de addiction camp

Hypothesis: There is effectiveness of community de addiction camp among the participants

\section{RESEARCH DESIGN}

Qualitative experimental research design was adopted to test the hypotheses.

\section{A. Universe}

Participants of the community de addiction camp organized by the SKDRDP at Chamarajanagar town, the headquarters of Chamarajanagar District, Karnataka state between 17.12.2017-24.12.2017 formed the universe for the study. This camp had 103 participants enrolled in the community de addiction camp who formed the universe for the study(SKDRDP, 2018).

\section{B. Sampling Method and Selection of the Sample}

The 103 participants were given serial numbers from 1 to 103 based on the order of their registration at the camp, by the SKDRDP camp resource person. The Resource person assigned to each researcher a group of ten people through systematic random sampling, giving each researcher, participants numbered 1 to 10,11 to 20,21 to 30 and 31 to 40. Thus the four researchers took first forty participants as per their registration number as the sample for the study. These forty participants formed the sample for the study.

\section{Tools for the Study}

1. AUDIT (Alcohol Use Disorders Identification Test, WHO, 2001) to identify the degree of severity of addiction of the community de addiction camp.

2. Interview schedule prepared by the researchers to get the back ground information about the participants their the history of their alcohol addiction

3. Participant Observation with regard to participation and behavior of the participants of the camp.

\section{Process of Data Collection}

The researchers were present along with the trainers and participants during the whole camp period. They administered AUDIT to identify the degree of addiction severity on the first and second day of the camp. They conducted the interviews with the participants, observed their participation and behavior in all the planned therapeutic activities of the camp as well as their leisure time behaviors. Post camp feedback from the participants was taken. All the participants were met 1 month after the camp to get the feedback regarding their level of abstinence done.

\section{E. Analysis of Data}

The data pertaining to the sample of forty respondents gathered thrice- first time, during the registration to the community de addiction camp, second time- at the end of the camp and the third time, one month after the camp. To Test the hypothesis, matched pair t- test is used.

\section{RESULTS}

The background information related to the respondents as gathered from the interview schedule revealed that majority of respondents $(70 \%)$ belonged the age group of $20-39$ years, majority of respondents had studies up to maximum 
of $10^{\text {th }}$ standard, most of the respondents held petty jobs, work for daily wages which are mostly unskilled jobs, $75 \%$ were married, $60 \%$ were having children who were getting educated, $52.2 \%$ respondents had adopted permanent family planning methods, most of the respondents belonged to Hindu religion, $95 \%$ were having BPL cards, $90 \%$ of them living in their own house, from villages in and around Chamarajanagar, $62.5 \%$ having small land holdings of dry land, $57.5 \%$ of which is irrigated by rain water, $60 \%$ had taken money from petty loans from money lenders, and finance companies at varying levels of interest, most of them were spending their earnings on alcohol. $50 \%$ had been in the habit of saving money. $62.5 \%$ of the respondent's spouses were members of SHGs run by SKDRDP organization. From the back ground information of the participants, it is seen that the respondents are rural inhabitants, poor, low educational level, unskilled, married men, who have indulged in spending most of their earnings on their alcohol addiction, have taken loans to fulfill their family responsibilities. It is to be noted that given their family and financial condition, most of them would not have been able to go for hospital based treatment for de addiction. The community de addiction camp has come as a boon to the respondents and their families.

\section{A. Information Regarding the Alcohol Consumption Habit of Respondents}

$30 \%$ respondents were in the habit of consuming alcohol for about 5-10 years duration and $25 \%$ respondents were in the habit of consuming alcohol for about 1 to 5 years. $72.5 \%$ of the respondents reported that their parents consumed alcohol. $92.5 \%$ of participants were in the habit of daily drinking. $75 \%$ of the participants desired frequent alcohol consumption, $57.5 \%$ of community de addiction participants felt the need to consume more quality of alcohol to get the kick. $50 \%$ of respondents had the habit of morning drinking.
$70 \%$ of the respondents identified that their alcohol addiction was a problem.

TABLE I ALCOHOL USE DiSORDERS IDENTIFICATION TEST (AUDIT) SCORES OF THE RESPONDENTS

\begin{tabular}{|c|c|c|c|}
\hline S. No. & Audit Score & Frequency & Percent \\
\hline 1 & 8 To 15 & 17 & 42.5 \\
\hline 2 & 16 To 19 & 11 & 27.5 \\
\hline 3 & 20 Above & 12 & 30 \\
\hline Total & 40 & 100 & 100 \\
\hline
\end{tabular}

Table I depicts the level of addiction among the respondents. $42.5 \%$ of the respondents had AUDIT score of 8 to $15.30 \%$ of the respondents had AUDIT score of 20 and above. $27.5 \%$ of the respondents had AUDIT score of 16 to 19. According to the AUDIT Scores interpretation, $42.5 \%$ of the respondents between 8 and 15 are most appropriate for simple advice focused on the reduction of hazardous drinking of participants in the community de addiction camp. $27.5 \%$ of the respondents had AUDIT score of 16 to 19 suggestive for brief counseling and continued monitoring in the community camp. $30 \%$ of the respondents had AUDIT score of 20 and above indicating diagnostic evaluation for alcohol dependence.Audit scores indicated that nearly $50 \%$ of participants came under the category of hazardous drinking who required advice to reduce the alcohol consumption, followed by $27.5 \%$ of respondents who needed brief counseling and monitoring in the community camp. Only $30 \%$ of participants required serious intervention for alcohol addiction. From this data, it can be deciphered as the camp was able to attract the people who were in the early stages of hazardous drinking which could have developed into serious addiction, in the absence of any intervention. Thus the community camp has helped the participants in preventing further deterioration in their addiction.

TABle Ii Before \& After Scores Of The Respondents About The EXPECTATION From The Community CAmP

\begin{tabular}{|c|l|c|c|c|c|c|c|}
\hline \multirow{2}{*}{ S. No. } & \multicolumn{2}{|c|}{ Expectations } & \multicolumn{3}{c|}{ Before } & \multicolumn{3}{c|}{ After } \\
\cline { 3 - 8 } & & Mean & N & Std. Deviation & Mean & N & Std. Deviation \\
\hline 1 & Discipline in daily routine & 5.6 & 40 & 2.4474 & 9.5 & 40 & 0.6794 \\
\hline 2 & Good sleep & 5.718 & 39 & 2.2118 & 9.44 & 39 & 0.68 \\
\hline 3 & Good appetite \& proper food intake & 6.375 & 40 & 2.1446 & 9.4 & 40 & 0.7442 \\
\hline 4 & Physical heath level & 5.282 & 39 & 2.2705 & 8.9 & 39 & 1.142 \\
\hline 5 & Hold over the addiction & 4.825 & 40 & 2.1589 & 9.35 & 40 & 0.6998 \\
\hline 6 & Improvement in health condition & 5.65 & 40 & 2.4131 & 9.025 & 40 & 1.025 \\
\hline 7 & Peace of mind \& reduction in craving & 5.075 & 40 & 2.2001 & 9.05 & 40 & 0.6775 \\
\hline 8 & Harmonious relationship with family & 5.85 & 40 & 2.3375 & 9.275 & 40 & 1.1764 \\
\hline 9 & Harmonious relationship at place of work & 5.325 & 40 & 1.8171 & 9.25 & 40 & 0.8987 \\
\hline 10 & Development new interests/hobbies & 4.325 & 40 & 2.4535 & 9.075 & 40 & 0.7642 \\
\hline 11 & Making good friends & 4.125 & 40 & 2.3004 & 8.775 & 40 & 1.025 \\
\hline 12 & Control/Removal of addiction habit & 4.95 & 40 & 2.5415 & 9.425 & 40 & 0.636 \\
\hline 13 & Any other & 4.775 & 40 & 1.702 & 8.85 & 40 & 1.122 \\
\hline
\end{tabular}


Table II reveals the information pertaining to the participant's expectation with regard to various changes in thirteen areas behaviors in community de-addiction camp. The expectation was measured through 1 to 10 scale. For the purpose of coding, scores 1 to 3 were consider low level of satisfaction 4 to 6 average level of satisfaction 7 to 10 extremely satisfactory. Paired t-test was conducted to find out whether there was any difference between the expectations of the respondents for these thirteen parameters before and after the community camp. There is an increase in the level of satisfaction in all the thirteen parameters.

Table Iit T-Test Between Before And After Mean Scores With Regard To EXPeCtations From The Camp

\begin{tabular}{|c|l|l|c|c|c|c|c|}
\hline \multirow{2}{*}{ S. No. } & \multicolumn{2}{|c|}{ Paired Difference expected Changes } & \multicolumn{2}{c|}{ Paired Differences } & \multicolumn{3}{c|}{} \\
\cline { 5 - 8 } & & Mean & Std. Deviation & t-value & d f & Sig. (2-tailed) \\
\hline 1 & Discipline in daily routine & Before and after & 3.9 & 2.296 & 10.743 & 39 & 0 \\
\hline 2 & Good sleep & Before and after & 3.7179 & 2.2355 & 10.386 & 38 & 0 \\
\hline 3 & $\begin{array}{l}\text { Good appetite \& proper food } \\
\text { intake }\end{array}$ & Before and after & 3.025 & 2.106 & 9.084 & 39 & 0 \\
\hline 4 & Physical heath level & Before and after & 3.6154 & 1.9684 & 11.47 & 38 & 0 \\
\hline 5 & Hold over the addiction & Before and after & 4.525 & 2.0379 & 14.043 & 39 & 0 \\
\hline 6 & Improvement in health condition & Before and after & 3.375 & 2.2836 & 9.347 & 39 & 0 \\
\hline 7 & $\begin{array}{l}\text { Peace of mind \& reduction in } \\
\text { craving }\end{array}$ & Before and after & 3.975 & 1.8465 & 13.615 & 39 & 0 \\
\hline 8 & $\begin{array}{l}\text { Harmonious relationship with } \\
\text { family }\end{array}$ & Before and after & 3.425 & 2.3739 & 9.125 & 39 & 0 \\
\hline 9 & $\begin{array}{l}\text { Harmonious relationship at } \\
\text { place of work }\end{array}$ & Before and after & 3.925 & 1.7598 & 14.106 & 39 & 0 \\
\hline 10 & $\begin{array}{l}\text { Development new interests } \\
\text { hobbies }\end{array}$ & Before and after & 4.75 & 2.3177 & 12.962 & 39 & 0 \\
\hline 11 & Making good friends & Before and after & 4.65 & 2.007 & 14.653 & 39 & 0 \\
\hline 12 & $\begin{array}{l}\text { Control/Removal of addiction } \\
\text { habit }\end{array}$ & Before and after & 4.475 & 2.4494 & 11.555 & 39 & 0 \\
\hline 13 & Any other & Before and after & 4.075 & 1.3471 & 19.132 & 39 & 0 \\
\hline
\end{tabular}

As seen in Table III, it is found that there is statistically significant difference in the mean scores on all parameters between before and after de addiction camp. Thus the null hypotheses are rejected that there was no difference in the mean scores of the parameters under study, as $\mathrm{t}$-test value stands at $0.000<0.05$ which is significant at $5 \%$ level and hence justified the research hypothesis $\mathrm{H} 1$ for all the parameters. The therapeutic activities of the community de addiction camp have been effective in bringing about change in various expectations of the clients. The mean scores of all parameter are highly satisfactory during the post community camp than the mean scores at the time of registration. The community de addiction camp has succeeded in bringing about a positive change in the participants.

TABle Iv Mean And Standard Deviation Of Client Behavior SCORES AND PARTICIPATION SCORES BEFORE AND AFTER THE CAMP

\begin{tabular}{|c|l|c|c|c|c|}
\hline \multirow{2}{*}{ S. No. } & & \multicolumn{2}{|c|}{ Before } & \multicolumn{2}{c|}{ After } \\
\cline { 3 - 6 } & & Mean & Std. D & Mean & Std. D \\
\hline 1 & Client Behavior & 5.325 & 2.0679 & 9.7 & 0.4641 \\
\hline 2 & $\begin{array}{l}\text { Client } \\
\text { Participation }\end{array}$ & 4.727 & 1.7973 & 9.65 & 0.6222 \\
\hline
\end{tabular}

Further, it is observed that all forty participants were abstinent one month after the camp and none had relapsed. This finding was augmented by the family members and members of the ex addicts group formed by the SKDRDP called NavJeevansamithi. These findings show that the community de addiction camp was effective in maintaining abstinence at one-month interval after the conduct of the camp.

Table IV reveals the mean score and Standard deviation from the mean scores for client behavior and participation before and after the camp. The mean score of client behavior was 5.325 before the camp. The mean score of participation was 4.727 before the camp. These scores indicated average level of behavior and participation. The mean scores increased to 9.7 and 9.65 for behavior and participation respectively after the camp. These scores indicate that the camp exposure had a positive impact on the behavior and participation of the participants. Majority of respondents were highly satisfied with the various therapeutic activities and the logistics provided at the community camp namely Advice by subject experts(92.5\%), Planned therapeutic group activity(85\%), Daily activity schedule( $82.5 \%)$, Time management in the camp (82.5\%), Food and hospitality(82.5\%), Discipline in the camp(77.5\%),Availability of First Aid and Doctor(77.5\%), Co participants Interaction(60\%), Interaction with volunteers(60\%) and Facility for drinking water, bathroom, toilets and hygiene(50\%). Among the various therapeutic activities carried out during the camp, the activities that made huge impact of the respondents were 
the ritualistic cremation of addiction habit by burning the habit symbolically, recreation programs and motivational speech session respectively.

\section{B. Post Group Results}

The SKDRDP had organized follow up meeting one month after the camp on 24.01.2018. During the first monthly meeting, the researchers went to meet the participants of the camp. They held post group evaluation with the campers. It was noted that none of the camp participants had relapsed during the intervening period and abstinence was at $100 \%$ level. The participants were very much motivated to remain abstinent and the group morale was very high.During the post group the researchers asked respondents whether they had desire/ craving to consume alcohol. $100 \%$ of the respondents expressed that they don't have desire to consume alcohol. The respondents reported that after leaving alcohol addiction, majority of them reported that they had positive family relationships, health, economic stability in the family and respondents also reported that they had good social status.

Most of the respondents came to the camp unaware of the camp purpose, expecting to stay for a day or two and many had not considered their alcohol intake as causing a problem to themselves or their families. In this context, it is seen that many of them wanted to get out of the camp in the initial two days, many were angry with their family members for making them to join the camp, few were threatening legal action also. But as the camp progressed, all of them gradually had a change of mind, understood the negative impact of alcohol on their personal life and health. They decided to stay on to improve upon their physical, mental, financial, family and social health (the issues addressed in various therapeutic activities of the camp) and they have given the overall rating of high level of satisfaction to the organization of the camp. Any service provided is measured through consumer satisfaction. The results reveal that the participants were highly satisfied with the therapeutic services provided in the camp. This is one of the indications of the effectiveness of the community de addiction camp. All these results indicate that the community de addiction camp has had a positive impact on its participants. It has helped the participants to maintain abstinence for one month after the camp.

\section{CONCLUSION}

Sell (2003) reports that community de addiction camps have been found to be remarkably successful and rates of abstinence are anywhere between 60 to $80 \%$. The current study also gives a very positive impact of community de addiction camp on its participants. Through these results, it can be concluded that the community de addiction camp has been effective in its de addiction effort. The community de addiction camp approach can give relief to people addicted to alcohol in rural areas in a cost effective manner.

\section{REFERENCES}

[1] Chand P., Naveen, C K., Murthy P., Isaac M. (2013). Addressing alcohol addiction: lessons from a hospital based audit. Indian J Med Res [serial online] [cited 2019 May 11];137:394-6. Retrieved from: http://www.ijmr.org.in/text. asp?2013/137/2/394/109573

[2] Chavan S. B., Gupta, N., Lok Raj., Arun, P \&Chanderbala (2003) Camp Approach - an Effective, Alternate Inpatient Treatment Setting For Substance Dependence: A Report from India. German J psychiatr y, 6, 17-22. Retrieved from http://www.gjpsy.uni-goettin gen.de/gjparticle-chavan.pdf retrieved on 13.05.2018

[3] Datta S., Prasantham B J., \&Kuruvilla K. (1991). Community treatment for alcoholism. Indian Journal of Psychiatry, 33. 305-306.

[4] Lok Raj., Chavan, B S. \&Bala C. (2005). Community 'de-addiction' camps: A follow-up study. Indian Journal of Psychiatry, 47(1), 4447. Jan-Mar, doi: 10.4103/0019-5545.46074

[5] Nithin Kumar., TanujKanchan., BhaskaranUnnikrishnan., RekhaThapar., PrasannaMithra., VamanKulkarni., Mohan Kumar Papanna., Ramesh Holla., Saran Sarathy. (2013). Profile of Substance Use among Patients Attending DeAddictionCentres in a Coastal City of Southern India. PLOS ONE. 8(2). Retrieved from e57824. file:///E:/e/project\%20dissertation/Project\%202018/Deaddiction/journ al.pone.0057824.PDF accessed on 08.01.2018

[6] Purohit, D R., \&R azdan, V K. (1988). Evolution and appraisal of community camp-approach to opium detoxification in North India. Indian Journal of Social Psychiatry, 4, 15-21.

[7] Chavan.,Sudarshan., Gupta., Nitin., Raj., Lok., Arun., Priti., \&Chandebala, A. (2003). Camp Approach - an Effective, Alternate Inpatient Treatment Setting For Substance Dependence: A Report from India. German Journal of Psychiatry, 6. 17-22.

[8] RanganathanS.(1994). The Manjakkudi experience: A camp approach towards treating alcoholics. Addiction. 1994;89: 1071 -5 [PubMed]

[9] SKDRDP (2018). Retrieved from https://skdrdpindia.org/programmes /accessed on 20.03.2018

[10] Sell H.(2003). The Open Community Approach to drug abuse control. Retrieved from www.unodc.org/documents/india/ddch9.pdf$31 \mathrm{k}-2003-04-28$

[11] Tonse, U.,\&Sinu, E. (2012). Quality of Life of Alcohol Dependents after Community Based Camp Intervention in the Treatment of Persons with Alcohol Dependence Syndrome. International Journal of Applied Research \& Studies, 1(3). 1-15.ISSN 2278-9480

[12] World Health Organization (2004). Global status report: alcohol policy. Geneva: Department of Mental Health and Substance Abuse, World Health Organization; 2004. p. 209.

[13] World Health Organization(1980). Problems related to alcohol consumption. Geneva: World Health Organization; 1980, 10-6. (WHO technical report series no. 7:650)

[14] World Health Organization(2002). The World Health Report 2002reducing risks, promoting healthy life.Geneva: World Health Organization; 2002. p. 250. [PubMed] 